\title{
Teaching Of Administrative Law In The New Grade Of Law
}

Patricia Domínguez Alonso, Ph.D., University of Castilla-La Mancha, Spain

\begin{abstract}
The teaching of Administrative Law in the new grade of law poses numerous challenges and opportunities in the new model of Bolonia. It's really important work of research and students in class presentations.
\end{abstract}

It is also important to get motivate students to study the issues and cases brought before classes and using virtual platforms to interact with students.

Keywords: Administrative Law; Teaching; Class Presentations

\section{THE EUROPEAN HIGHER EDUCATION AND THE ECTS CREDIT SYSTEM}

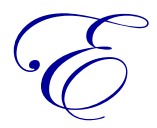

uropean Convergence in higher education involves recognizing that the construction of Europe should take steps, not only in commercial and labor, but also at the intellectual, cultural, scientific and technological development, an idea that is realized for the first time in the Sorbonne Declaration of May 25, 1998, signed by education ministers from Germany, France, Italy and the UK. The subsequent Bologna Declaration of 1999 is, as you know, the starting point of a process of change that can be considered one of the most intense and important of all who have lived the Spanish university in its long history.

The European Higher Education Area (EHEA) is a project launched by the European Union to harmonize European university systems, so that all have a homogeneous structure of undergraduate and graduate degrees, the same assessment of the workload of the studies courses and subjects and grades are similar. It represents, in terms borrowed from DE PABLOS PONS, "a joint effort to reform the university, by the European countries, which revolves around two key areas: generating a set of structural changes from the so-called Bologna process which involves a curriculum renewal and methodology and the implementation of ECTS and the Diploma Supplement called, to facilitate transparency and mobility of university degrees proposal arranged in three levels (bachelor, master and doctorate) and ensuring the quality accreditation. The second axis refers to the strategic changes necessary to enable European universities to better respond to the demands of employment, social cohesion and competitiveness of European countries. "

The new European university system has as one of its basic elements using the European Credit Transfer System (ECTS, an acronym that means European Credit Transfer System) is the new concept of assessment of university education. Born and developed with the European exchange program ERASMUS-SOCRATES students. With the implementation of the EHEA, the concept of credit will change, no longer identifies with the duration of the classes taught by the teacher, but with the total volume of work that the student required to complete the course. This system includes the hours of theoretical and practical class, the effort devoted to the study, preparation and conduct of examinations.

Although never be treated as an underestimation of learning content and concepts, the European Credit is also giving due importance to the learning of skills, abilities and skills. A more or less precise knowledge of what should be these skills is essential when you know what must be taught and, above all, how. Current curricula do not say anything about it, unlike what happened with other degrees. However, from the unfinished worked developed by the working group established at the initiative of the Conference of Deans of law schools in Spain, is considered to include among the powers, abilities and skills to develop in our degree, at least the following: capacity for analysis 
and synthesis, capacity for organization and planning, capacity management information, oral and written, problem solving, decisiveness, teamwork, critical thinking, ethical, autonomous learning, social sensitivity, economic and environmental, creativity, entrepreneurship, leadership, etc..

This cannot be interpreted, however, as a closed and exhaustive catalog. Quite the contrary, the process of implementing the European Credit should serve to stimulate discussion in the faculty about pursuing graduate profile, which will undoubtedly result in a concrete and an extension of knowledge to acquire, and skills, abilities and skills to develop. And all this without forgetting that, as FONT clear, the goal of teaching in the case of law schools should be to allow the student:

a) Be an idea to form an opinion about political and social phenomena governing the right.

b) Know how the law regulates such situations and understand why.

c) Be able to apply or criticize such regulation to consolidate and innovate, the existing situation.

\section{THE TEACHING OF ADMINISTRATIVE LAW: THE NECESSARY FEEDBACK BETWEEN TEACHING AND LEARNING}

The challenges of the Bologna process and the establishment of the EHEA are not so much in inventing new teaching techniques, as in proper combination, in the proper proportion between them, in the definition.

The educational objectives of the new higher education model are summarized in a phrase that has become successful and has become a sort of slogan of the Bologna Process "Learning to learn". The law schools have to provide only a knowledge that can (and indeed will) become obsolete over a period of time more or less brief. The goal is to provide the tools for acquiring knowledge. The goal is that students learn skills, competencies and skills. To do this, the formulas to articulate this teaching are varied and have probably vary from one center to another, depending on the student profile and depending on the specific demands that arise in this center.

So, as teachers, the new model requires us to develop better and more detailed planning of the program / $\mathrm{s}$ of the subject / s / s that are responsible for trying, on the other hand, an exercise of self-restraint to avoid exceeding or saturate the possibilities of student work normal. It also requires an important role in both horizontal and vertical coordination with the other responsible for the disciplines. Prepare an educational program of this nature requires some reflection by teachers because, in effect, particularly in the initial stages of study, characterized by confusion and general confusion among students, must work to provide certainty and transparency to the new teaching method so that students know from the beginning and a clear, what efforts, if anything, requires reasonably planned to pass the subject.

The teaching of subjects in the area of administrative law should be based on the combined application of a set of methods to balance the theoretical components and, above all, practical course of promoting, at the same time, the ability of student learning.

In this regard, while the European credit system aims to relegate the keynote address to the background, do not forget that administrative law is an essentially theoretical matter, without whose prior knowledge cannot move forward in resolving any problems practice. Hence, in our view, the method ECTS has to affect our discipline both teaching methods and the evaluation system, which itself can-be-introduced meius certain modulations.

These adaptations will revolve around the method of problem-based learning is presented as a paradigmatic example of the active methodologies of particular interest in the process of European convergence. This teaching method involves a shift from traditional media, not their abolition.

So, a parent must be tracking one or more booklets. The lecture should be complemented with the implementation of a number of other techniques such as case discussions, readings and visits to institutions and should be supported in conducting tutorials and seminars on specific topics. All using the new technologies and, in particular by using the resources for this purpose, offered by the University of Castilla-La Mancha through Virtual Campus, which result in platforms such as Red-C @ mpus, WebCT or more recently, Moodle. 
Those methods will help the students develop the skills needed to deal with situations of disagreement and uncertainty, as you normally have to solve in his future career.

The problem-based learning is based on three key objectives of higher education: a) the acquisition of knowledge that can be retained and is capable of being used, b) autonomous learning, c) learn to analyze and solve problems. It is actually a method very similar to the following scientists and other professionals in practice, including those legal professions, as is the application of prior knowledge to a case or set of facts, in order to define one or more problems, for whose resolution will have to set goals for learning, which is then tested against to achieve a result (a report, a proposal, a claim, appeal, etc..).

This method, in its different forms and adapted always the teacher to the characteristics of the subject being taught, can develop skills of analysis, thoughtful discussion, strategy development, legal reasoning, reporting and other very useful for the subsequent performance of professional duties of our students.

The elements necessary to carry out this training method are:

a) A case or set of facts, which is prepared by the teacher in relation to the subject being taught and to create a cognitive conflict in the student (a question, problem, a strategy, a task).

b) Some prior knowledge, which are activated by the process of thinking about the problem, the fact of having to study more thoroughly and with a tangible purpose.

c) The organization of the class in one or more groups, with six the number of students per group recommended.

The work is divided into four phases. The first is of prior discussion in the classroom or seminar. The group will follow, in that order, to clarify difficult or vague terms, define the problem, analyze it through a "brainstorming" to achieve a systematic inventory of issues and, finally, formulate specific learning objectives in its case, are distributed. The second phase is individual study, drawing on sources (manuals, codes of law and jurisprudence) in the library, by computer, etc.. In the next session in the classroom as well, each member has to inform the group of the result of acquired knowledge, to achieve a synthesis and report. This can be presented to other groups and subjected to debate or sharing, to be finally delivered to the teacher.

It is important that within the group, on a rotation basis, one assumes the role of facilitator, responsible for ordering the discussion, encourage participation of all, control the weather, check the agenda. Another member has to act as secretary, in charge of recording all relevant information, raising some kind of record for the next meeting and completed the work, preparing the report and expose.

A third role is that of teacher, although at a distance, with restraint, as it must be the one to guide and stimulate the learning process based on their expert knowledge and the process and group interaction, but displace or substitute for the students. The teacher must help students in the discussion phase before establishing hypotheses, clarify ideas, fix bugs, structure information and notice the gaps, identify learning objectives. It is important that the teacher guides the individual study, indicating sources and readings appropriate to avoid waste of time. Then in the synthesis phase, is to help separate the essential information of the marginal, develop critical thinking, encourage indepth discussion and encourage the application of knowledge. The presence of the teacher is essential in the phases of group work, both to facilitate the learning process (listening, asking questions, alternatives, consequences, offering analogies, metaphors, counterexamples, doing the devil's advocate) and the dynamics or operation Group (distribution of functions, foster collaboration, correct any problem behaviors, stimulate the task).

For this reason, the teacher's behavior may compromise the group's interaction, so you must avoid excessive intervention, signs of disapproval, a leading position to make decisions on targets and sources of learning or to "mini-classes".

The teacher's behavior is one of the factors that influence the process of problem-based learning. So are the quality of the cases which have been prepared to encourage or discourage intrinsic interest, and prior knowledge that students have. The quality of the working group can be decisive as well as independent study students engaged in 
learning the objectives marked. The end result will be a combination of these factors, although, as happens to any other method, it is important not to get discouraged at the first hurdle, because the experience is improved.

This method has the risk that the subject knowledge will be less systematic and more limited in extent, but in return has numerous advantages. The first is, of course, that is consistent with the natural process of human learning. The activation of prior knowledge facilitates the learning process and can learn thinking, reflecting, questioning, discussing, constructing new knowledge. Furthermore, when new information is acquired in relation to a context and stored along with it increases the memory alone, without exacerbating the memory. It also facilitates the recall of information on learning activities that have an operational sense, when they result from the development and understanding, rather than mechanical repetition. Furthermore, the knowledge thus constructed, elaborated and contextualized has to be transferred and, therefore, accompanied by the development of communication skills.

Experience shows that this method provides greater motivation and interest of students, who have to take an active and disciplined, in addition to caring for their study skills. This is aided, no doubt, teamwork, less monotonous and boring that isolation, and in turn develop argumentative skills, role performance, collaborative work.

\section{AUTHOR INFORMATION}

Patricia Domínguez Alonso, Ph.D. in Law by Autonoma University of Mexico State and Degree in Law by University of Castilla-La Mancha. Asistent Professor of Administrative Law at Public Law Department. Faculty of Social Sciences of Cuenca. University of Castilla-La Mancha (Spain). Research Interest: Environmental law, Water Law, administrative organization. E-mail: Patricia.Dominguez@uclm.es

\section{REFERENCES}

1. Capella, J. R. (1995): "Nothing provides the best student opportunity to learn that a good teacher", Learning Learning, Trotta, pp. 46-54.

2. De pablo, P. (2008): "General Introduction to the Strategic Analysis for European convergence", University of Seville, 25.

3. Font I. (2002): "Teaching, learning and education in administrative law", Proceedings of the XIII ItalianSpanish Congress of Administrative Law, Cedecs, pp. 31-32.

4. The importance of the Bologna Declaration (2001): On the same, KNUDSEN VI, Introduction to the Sorbonne Bologna Declaration, ELFA Newsletter 25. 